\title{
The relationship between rumination and sleep quality in patients with major depressive disorder
}

\author{
Samira Yadollahifar ${ }^{1}$, Amir Sadeghi $^{2}$, Farshid Shamsaei $^{3}$ \\ 1-MSc of Psychiatric Nursing, Students Research Center, Hamadan University of Medical Sciences, Hamadan, Iran. \\ 2- Associate Professor, Department of Nursing, Hamadan University of Medical Sciences, Hamadan, Iran. \\ 3- Associate Professor, Maternal and Child Care Research Center, Hamadan University of Medical Sciences, \\ Hamadan, Iran (Corresponding Author). $\quad$ E-mail: shamsaei68@yahoo.com
}

Received: 26/01/2020

Accepted: 04/04/2020

\section{Abstract}

Introduction: Sleep disorders one of the problems of patients with depression is that they may be associated with a number of factors, such as rumination.

Aim: The aim of this study was to investigate the relationship between rumination and sleep quality in depressed patients.

Method: The present study was a descriptive-correlational study. A simple random sampling method was used to select 160 patients with major depressive disorder at Farshchian Hospital in Hamedan in 2017. Pittsburgh sleep questionnaire was used to collect data. Data were analyzed using descriptive and inferential statistics (pearson and spearman correlation coefficient) and SPSS 23 software.

Results: The correlation between rumination and sleep quality in patients with major depressive disorder admitted in Farshchian hospital in Hamadan showed that Pearson correlation coefficient test showed a significant and direct relationship with 0.476 between rumination and sleep quality. So people who scored higher on the sleep quality questionnaire actually had lower sleep quality because of the reverse score. Data analysis showed that there was a significant relationship between rumination and sleep quality $(r=-0.476, p=0.001)$.

Conclusion: The present study showed that there is a significant relationship between rumination and sleep quality in depressed patients and rumination leads to decreased sleep quality in patients. In depressed patients, sleep quality is more important and it is necessary to improve their health through strategies such as rumination therapy.

Keywords: Rumination, Sleep quality, Major depressive

How to cite this article : Yadollahifar S, Sadeghi A, Shamsaei F. The relationship between rumination and sleep quality in patients with major depression admitted in Farshchian Psychiatric Hospital in Hamadan. Shenakht Journal of Psychology and Psychiatry. $2020 ; 7$ (2): 26-36 .URL: http://shenakht.muk.ac.ir/article-1-732-fa.pdf

Copyright (C) 2018 the Author (s). Published by Kurdistan University of Medical Sciences. This is an open access article distributed under the terms of the Creative Commons Attribution-Non Commercial License 4.0 (CCBY-NC), where it is permissible to download, share, remix, transform, and buildup the work provided it is properly cited. The work cannot be used commercially without permission from the journal. 


\title{
بررسى ارتباط نشخوار فكرى با كيفيت خواب بيماران مبتلا به افسردكى اساسى
}

\author{
سمير ايداللهى فر '، امير صادقى '، فرشيد شمسائى \\ ا. كارشناسى ارشد روان يرستارى، مركز تحقيقات دانشجويى، دانشكاه علوم يز شكى همدان، همدان، ايران.

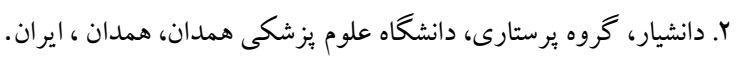

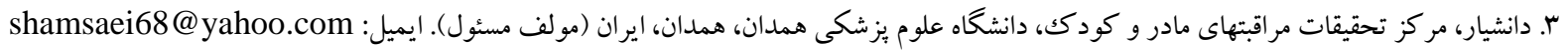

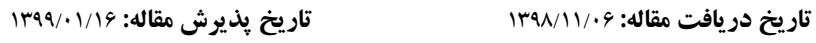

\section{جكيده}

مقدمه: اختلال در خواب يكى از مشكلات بيماران با اختلال افسردگى است كه با عوامل متعددى از جمله نشخوارى فكر ممكن است ارتباط داشته باشد. هدف: اين مطالعه با هدف بررسى ارتباط بين نشخوار فكرى با كيفيت خواب در بيماران افسرده اساسى انجام شد.

روش: روش ثُزوهش حاضر توصيفى- همبستگى بود. روش نمونه گيرى تصادفى ساده بود كه .19 نفر از بيماران افسرده اساسى در

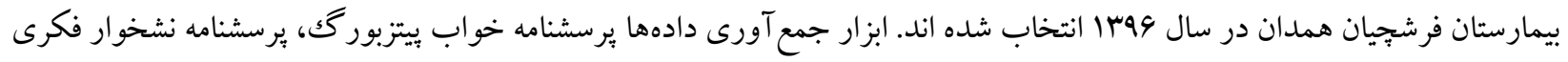
نالن هاكسما است. تجزيهو تحليل دادهها با استفاده از آمار توصيفى و استباطى (ضريب همبستكى بيرسون و اسبيرمن) و نرم افزار SPSS

يافتهها: در بررسى آزمون رابطهاى بين نشخوار فكرى با كيفيت خواب بيماران افسرده اساسى بسترى شده در بيمارستان فرشجيان

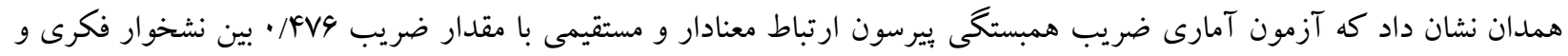

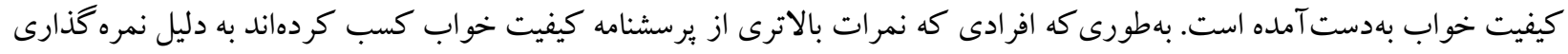

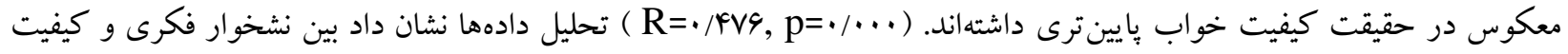

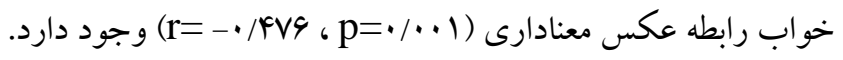
نتيجه كيرى: يُزوهش حاضر نشان داد كه بين نشخوار فكرى و كيفيت خواب در بيماران افسرده ارتباط معنادار و عكسى وجود دارد و نشخوار فكرى منجر به كاهش كيفيت خواب بيمار ان مىشود. در بيماران افسرده كيفيت خواب از اهميت بيشترى برخوردار است و لازم است با راهكارهاى ازجمله درمان نشخوار فكرى سلامتى آنها را ارتقاء داد. كليدوازهها: نشخوار فكرى، كيفيت خواب، افسردگى اساسى 
قرارگرفته است. يكى از انواع افكار ناخواسته در اختلالات هيجانى نشخوار فكرى است. ديدكاه فراشناختى اختلالات هيجانى، نشخوار فكرى را يكى از مؤلفهاى اصلى در شروع و تداوم افسردگى مىداند

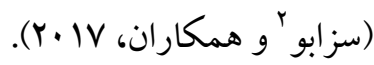
نشخوار فكرى بهعنوان افكارى مقاوم و عود كننده تعريف مىشود كه گرد يكك موضوع معمـول دور مىزند. اين افكار به طريق غيرارادى، وارد آكاهى مىشوند و توجه را از موضوعات موردنظر و اهداف فعلى منحرف مىسازند

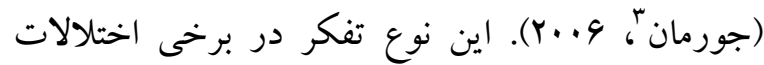

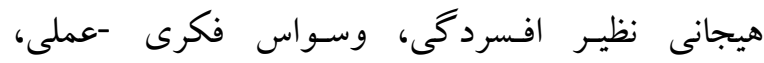
اضطراب فراگيـر و اخـتلال استر س يسـ از حادثـه مشاهده مىشود (سزابو و همكاران، Y.IV). نشخوار فكرى زيربناى شناختى بيماران افسرده رادجار ناهنجارى

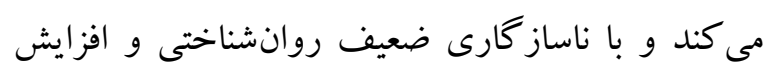
احساسات منفى مانند خشم و فشار روانى رابطه دارد

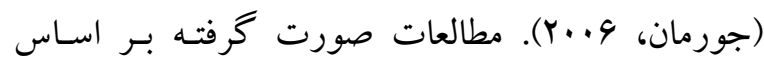

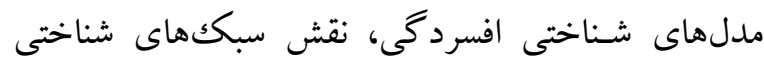
منفى و نشخوار فكرى را بهعنوان عوامل خطرساز

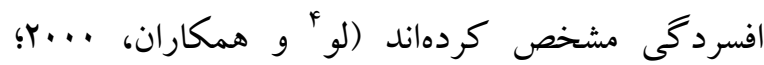

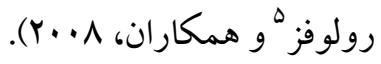

هايدى و همكاران نشخوار فكرى را بهعنوان يكى از

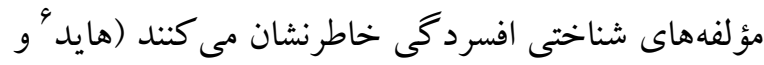

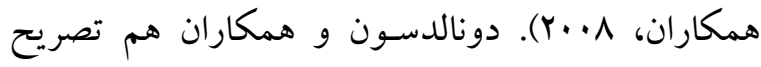
مى كنند كه افسردگى بـا يـك سو گيرى توجهى به سمت اطلاعات منفى در راستاى ارزيـابى از خـود همـراه اسـت. ايـن سـو گيرى منفى در آن دسـته از بيمارانى كه

2. Szabo

3 - Joormann

${ }^{4}$ - Lo

5 - Roelofs

${ }^{6}$ - Hyde مقلdمه افسردگى يكك بيمارى رايج در سراسر جهان است كه بيش از ..ب ميليون نفر از مردم را تحت تأثير قرار

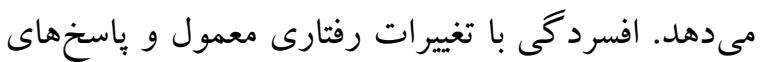

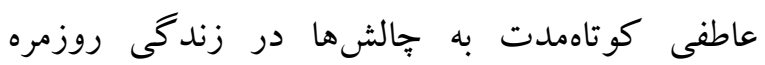

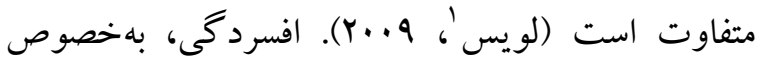
زمانى كه طولانىمدت و با شدت متوسط و شديد، ممكن است براى وضعيت سلامتى يكك تهديد كننده جدى باشد. اين باعث مىشود كه فرد مبتلا بهشدت رنج ببرد و فعاليتهاى اجتماعى در كار، مدرسه و در خانواده بهندرت تحت تأثير قرار دهد. در بدترين حالت،

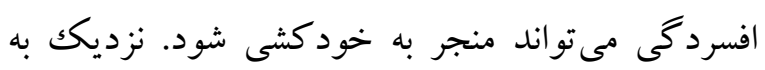
A...

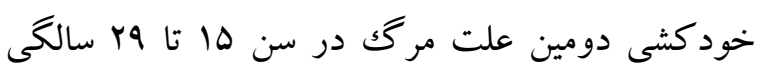
است (صادقى راد و همكاران، • · •r). افسردگى يكى از شايعترين اختلالات در ايران، اختلال در هزينهاى جهارم در جهان و بدون شكك دومين كرانترين اختلال تا سال ها ·r بوده است. برخى از ويز كى هاى جمعيت شناختى و اجتماعى افراد سالخورده افسردگى را كاهش يا افزايش ميددهند (ساراخانى و و

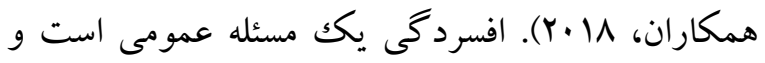
هr تا ها درصد بيمارىهاى روانى را در ايران تشكيل

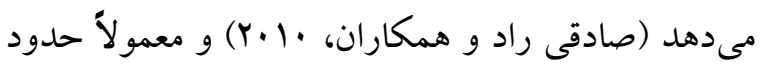

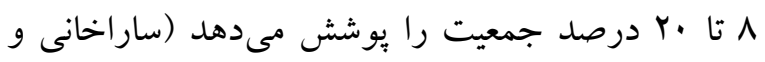

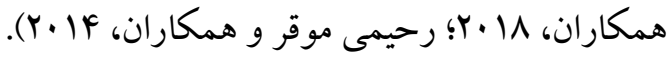
در سالهاى اخير بررسى الخوهاى تفكر در اختلالات هيجانى و بررسى افكار ناخواسته و نقش آن در دوام

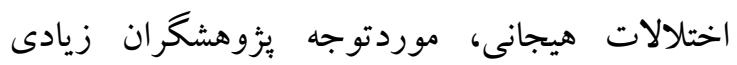

\footnotetext{
1. Lewis
} 
براى بيماران افسرده اساسى استفاده مىشود هشدار به اهميت رسيد گیى به شكايات خواب در اين جمعيت است. كيفيت خواب تحت تأثير عوامل مختلفى قرار دارد و

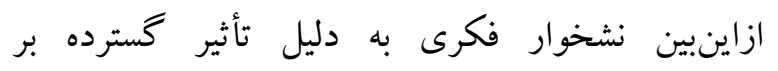
عملكردهاى روزانه فرد مىتواند كيفيت خواب بيماران افسرده را بيشتر تحت تأثير قرار دهد و يكى از انواع افكار ناخواسته در اختلالات هيجانى است كه ديد رئاه فراشناختى اختلالات هيجانى، نشخوار فكرى را يكى از

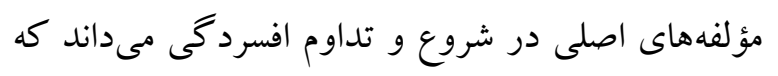
نياز به توجه جدى دارد. با توجه به اينكه تا كنون يزوهشهاى اندكى در زمينه بررسى ارتباط نشخوار

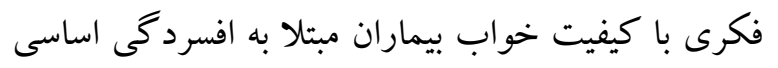
انجام شده است و به نظر مىرسد كه فراشناخت ها بتوانند بهعنوان عاملى مؤثر براى تبيين كيفيت خواب، بهويزه در

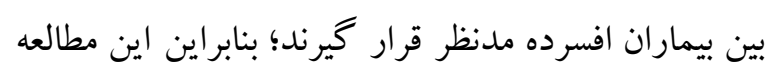
باهدف بررسى نقش نشخوار فكرى در كيفيت خواب بيماران افسرده انجام شد.

\section{روش}

روش يزٔوهش حاضر توصيفى- همبستگى بود. جامعه آمارى شامل بيماران افسرده اساسى در بيمارستان

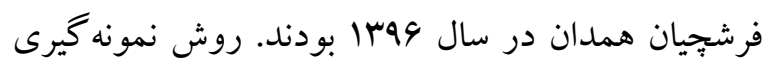
تصادفى ساده بود كه .19 نفر از بيماران افسرده اساسى در بيمارستان فرشجيان همدان در سال وهبا انتخاب G POWER- شدند. حجم نمونه با استفاده از نرمافزار 103 و با توجه به نوع آزمون (همبستكى بيرسون) با توان

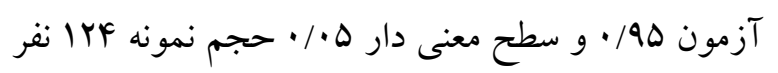

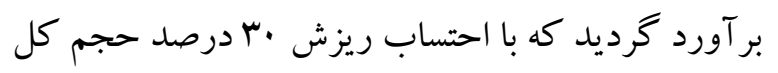
نمونه •19 نفر در نظر كرفته شد. معيار ورودد به مطالعه نداشتن معلوليت جسمى، نيازمند بسترى در بيمارستان
نشخوار فكرى دارند، قوىتر مىشود (دونالدسون' و

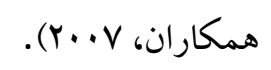
بهطور كلى افكار عود كننده منفى نقش بسزاى در ابتلا و

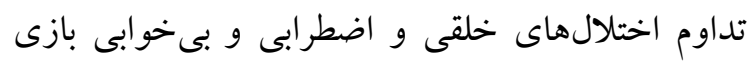

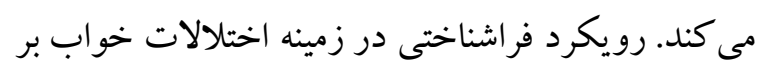
اين باور است كه افراد به اين دليل در دام بىخوابى و

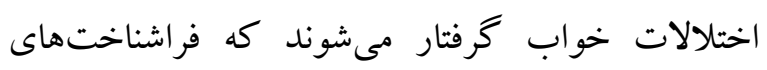
آنها به الكوى خاصى از ياسخدهى به تجربه هاى درونى منجر مىشود كه موجب تداوم هيجان منفى و تقويت باورهاى منفى مىشود. بيماران افسرده اغلب از نشخوار فكرى رنج مىبرند كه در لحظات ييش از به خواب رفتن نشخوارهاى فكرى بيشتر مىشود و بر كيفيت خواب آنان

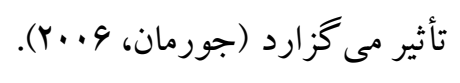

مطالعات نشان مىدهند نشخوار فكرى باكيفيت خواب و و خلق افسرده ارتباط دارد به طورى كه كيفيت خواب را كاهش داده و علائم افسردگى را تشديد مى كنند

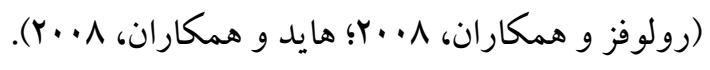

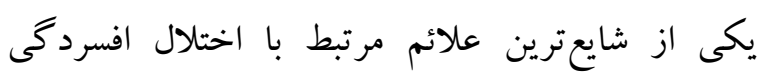
اساسى اختلال در خواب است مشكلات تنظيمات خواب به دليل بيمارى نيستند؛ در عوض، اغلب اوقات قبل از

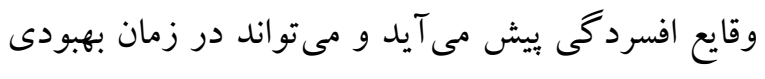
ادامه يابد. بهبود خواب در بيماران افسرده بهبوديافته است

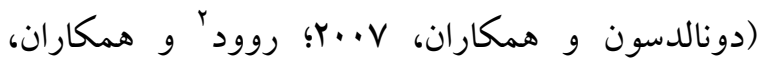

علاوه بر اين، محروميت خواب مىتواند قسمتهاى افسردگى را در افراد حساس ايجاد كند و علائم افسردگى را در افراد ديخر كاهش دهد. مشاهدات يثزوهشخران نشان مىدهد كه داروهاى خوابآور كه

1- Donaldson 
خو اب نامطلوب را نشان مىدهد (دونالدسون و همكاران،

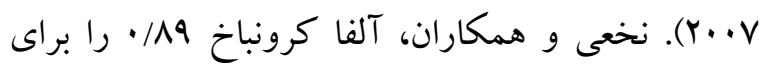

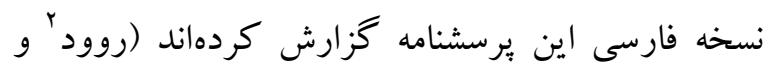

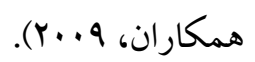
مقياس بإنخ نشخوار فكرى (RRS)" اين مقياس توسط نولن و هو كسيما و مورو، تدوينشده است و داراى بr سؤال است كه خلق افسرده را توصيف مى كند و هر سؤال آن بر روى يكك مقياس \& درجهاى از ا (تقريباً هركز) تا

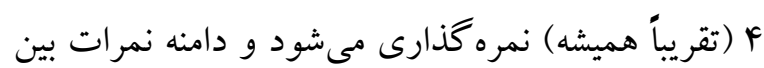

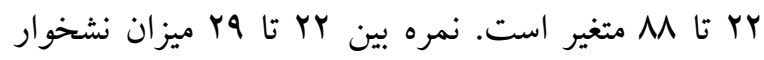
فكرى در حد بايينى دارند، نمره بين هو تا هـ ميزان

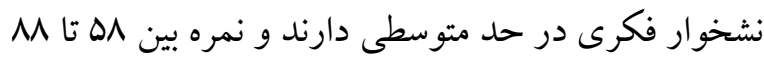
ميزان نشخوار فكرى در حد بالايى دارند. ضريب بايايى

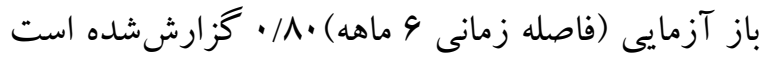
در ضمن بايايى همسانى (ضريب آلفاى كرونباخ) اين

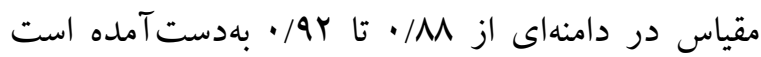

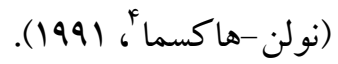

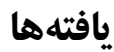

يافته ها در رابطه با متغيرهاى دمو گرافيك نشان داد

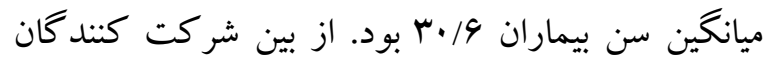

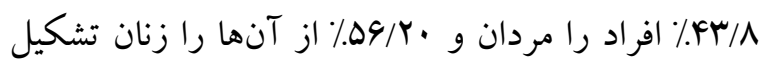
دادند. اكثريت آنها ساكن شهر و متأهل بودند و اكثريت آنها از نظر وضعيت تأهل، متأهل با مقدار عددى لـ/

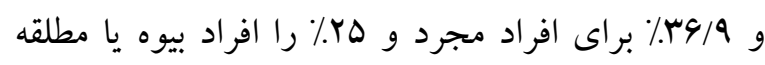

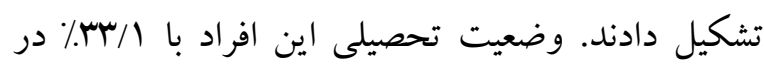

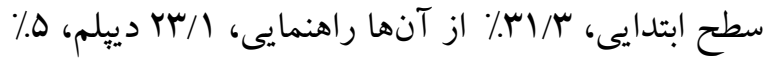
فوق دييلم و 9/9\% در مقطع ليسانس و 9\% در مقاطع بالاتر

2- Rood

${ }^{3}$ - Rumination Response Scale

${ }^{4}$ - Nolen-Hoeksema
فرشجيان بنا بر تشخيص روانيزشك باشد، بزركسال بودن بيمار، سابقه حداقل يكك سال بسترى، نداشتن

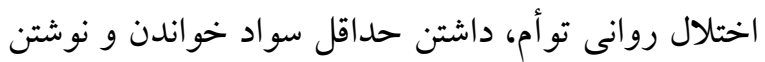
و رضايت جهت شركت در مطالعه بود. معيار خروج افراد از مطالعه نيز عدم همكارى آنها و درخواست آنها مبنى بر عدم همكارى است. جهت نمونه گيرى به بخشهاى روان، بيمارستان فرشجيان شهر همدان مراجعه شد و بيمارانى كه تشخيص دوقطبى نوع يكك بنا به نظر بزشك مُك مربوطه داشتند انتخاب شدند. تجزيه و تحليل دادهها با استفاده از آمار توصيفى و استنباطى (ضريب همبستكى بيرسون و اسييرمن) و نرم افزار SPSS نسخه سץ انجام ابزار جمع آورى دادهها برسشنامه خواب بيتزبورگ، يرسشنامه نشخوار فكرى نالن هاكسما است. يرسشنامه كيفيت خواب يِينزبوركى' (PSQI): اين برسشنامه به بررسى كيفيت خواب در F مغته كذشته مى بردازد و شامل 9 سؤال در V بخش (كيفيت ذهنى خواب، دير به خواب رفتن، كفايت خواب، دوره خواب، اختلال خواب، استفاده از داروهاى خوابآور و اختلال عملكرد طى روز (بهصورت مشكلات ناشى از بدخوابى كه توسط فرد در طول روز تجربه مىشود) بوده است. امتياز هر سؤال حداقل · و حداكثر ب است. مجموع ميانگين نمرات اين هفت جزء نمره كل ابزار را تشكيل

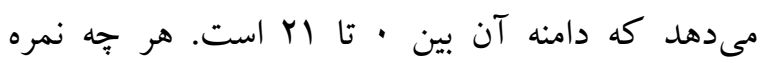
بهدست آمده بالاتر باشد، كيفيت خواب يايينتر است.

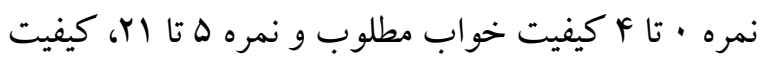

\footnotetext{
1- Pittsburgh Sleep Quality Index
} 
10..... درصدى تقريباً كمتر از آن حدود 19 •٪٪ ساكن روستا بودند. در بررسى طول مدت بيمارى، بيماران افسرده

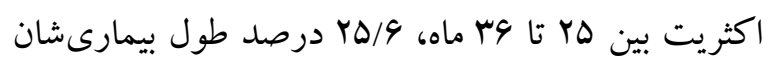
بود. در جدول ا توصيف متغير كيفيت خواب بيماران افسرده اساسى ذكرشده است.
از ليسانس بودند كه در اين ميان بيشترين درصد با مقدار عددى //سم/\% مربوط به مقطع تحصيلى ابتدايى بود. در

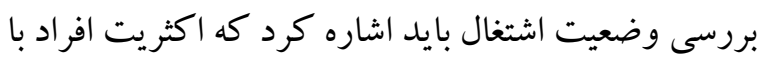

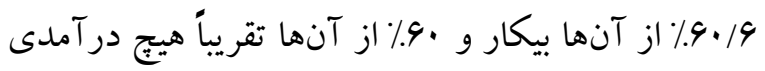
نداشتد و در صد كمى از آنها با مقدار عددى \&/\&٪ كارمند بودند كه بيشترين درآمدشان بين ل........ تأ

\begin{tabular}{|c|c|c|}
\hline انحر اف معيار & ميانكين & ابعاد كيفيت خواب \\
\hline.$/ 90$ & $1 / v$ & كيفيت ذهنى خواب \\
\hline $1 / \cdot 1$ & $1 / 9$. & تأخير در به خواب رفتن \\
\hline $1 / 11$ & $1 / 11$ & مدت زمان خواب \\
\hline.$/ 90$ & $1 / v$ & ميزان بازدهى خواب \\
\hline$\cdot / 09$ & $1 / 49$ & اختلالات خواب \\
\hline.$/ 9 V$ & $r / r q$ & استفاده از داروهاى خواب آور \\
\hline$\cdot|A|$ & $1 / \pi \Delta$ & اختلالات عملكردى روزانه \\
\hline F/va & $11 / r$ & كيفيت كلى خواب \\
\hline
\end{tabular}

است و در كل ميانگين كيفيت كلى خواب ( • (I/T) بوده است. در جدول Y همبستكى ابعاد خواب با نشخوار فكرى در نمونه مورد مطالعه ذكرشده است.
ميانگين و انحراف معيار كيفيت خواب بر اساس برسشنامه كيفيت خواب نشان مىدهد كيفيت خواب در بعد استفاده از داروهاى خواب آور ( (Y/Y) داراى بيشترين ميانگين و مدتزمان خواب (I/MA) داراى كمترين ميانخين بوده

\begin{tabular}{|c|c|c|}
\hline \multicolumn{2}{|c|}{ نشخوار فكرى } & \\
\hline سطح معنادارى & ضريب همبستكى & ابعاد كيفيت \\
\hline$<\cdot / \cdot \cdot 1$ & $-\cdot / \pi \vee \wedge$ & كيفيت ذهنى خواب \\
\hline.$/ \cdot 1$ & $-\cdot / r V I$ & تأخير در به خواب رفتن \\
\hline$\cdot / \cdot r V$ & $-\cdot / 1 V \Delta$ & مدتزمان خواب \\
\hline$<\cdot / \cdot \cdot 1$ & $-\cdot / \pi \mathrm{V} \wedge$ & ميز ان بازدهى خواب \\
\hline$\cdot \cdots \Delta$ & - & اختلالات خواب \\
\hline
\end{tabular}




\begin{tabular}{ccc} 
استفاده از داروهاى خوابآور & اختلالات عملكردى روزانه \\
\hline
\end{tabular}

و نشخوار فكرى و كمترين همبستگى بين بعد اختلالات تحليل دادهها نشان داد بين نشخوار فكرى و كيفيت

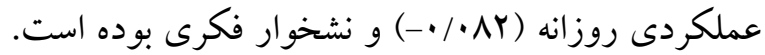
خواب رابطه عكس معنادارى وجود دارد. با كاهش با آزمون همبستگى اسبيرمن در جدول بم همبستگى

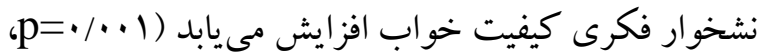
نشخوار فكرى با عوامل دمو گرافيك ذكر شده است. r=-•/FV9

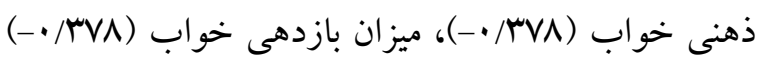

\begin{tabular}{|c|c|}
\hline سطح معنادارى & متغير \\
\hline - /49Y & جنس \\
\hline 1.04 & سن \\
\hline . $/ 4 q$ & وضعيت تأهل \\
\hline$\cdot 1 \cdot \cdot 1$ & سطح تحصيلات \\
\hline$\cdot / \cdot 1$ & وضعيت اشتغال \\
\hline$\cdot / \cdot r$ & طول مدت بيمارى \\
\hline.$/ \cdot 1$ & ميزان درآمد \\
\hline . / Fr & محل سكونت \\
\hline
\end{tabular}

يافتهاى مطالعه حاضر نشان داد نشخوار فكرى در //NF درصد از بيماران افسرده در سطح نامطلوب است كه اين يافته با نتايج يزوهشهاى واتكيزنز' وهمكاران (II (Y)؛

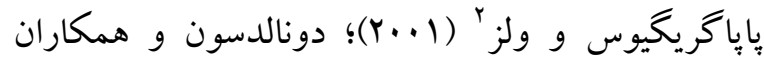

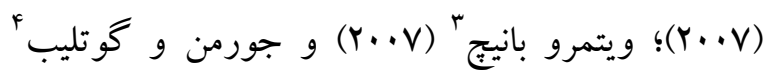
(Y.人) همخوانى دارد. واتكينز و همكاران نشان دادند كه القاء نشخوار در بيماران افسرده موجب توليد مستمر افكار محركك مىشود كه مانع از بردازش اجراى كارهاى
آزمون بيرسون تفاوت معنادارى بين نمره كل نشخوار فكرى بر حسب سن (4) (p= (p)، طول مدت بيمارى

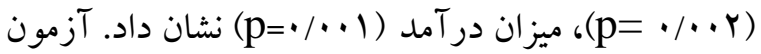
اسبيرمن بين متغير نشخوار فكرى با وضعيت تأهل

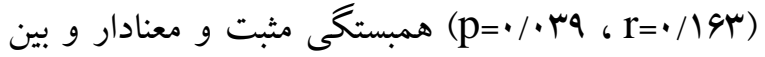

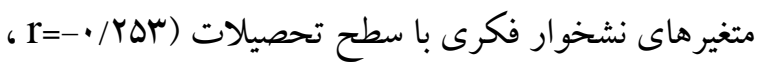

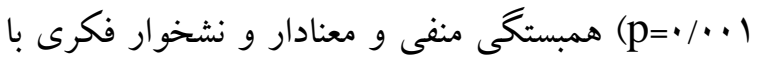

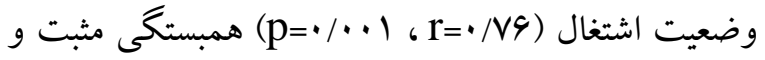
معنادار آمارى وجود دارد.

1- Watkins

2- Papageorgiou \& Wells

3. Whitmer \& Banich

4- Joormann \& Gotlib 
همكاران، 199V). مطالعه ون ميل و همكاران نشان داد كه اختلال افسردگى و همجنين اختلال اضطر ابى به شدت با اختلالات خواب مرتبط است (وان ميل " و همكاران، (Y.1). كيفيت خواب ضعيف و رفتار خود كشى در بيماران مبتلا

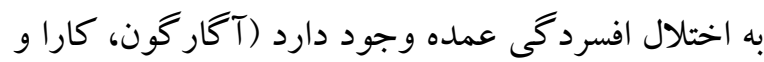

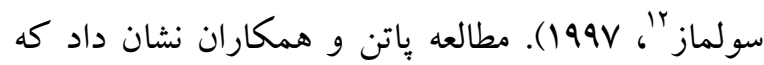
كاهش علائم افسردگى و سيگار كشيدن در ميان نوجوانان عو امل مهمى در ييشخيرى و درمان با توجه به وسيه

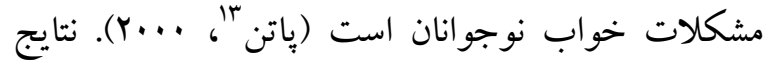
مطالعه ونگل و همكاران نشان داد كه بين نشخوار و ونو اختلال خواب مرتبط با استرس ارتباط وجود دارد. علاوه بر اين نارسايى خواب و اختلالات خواب مرتبط با استرس و مداخلاتى كه بر روى آنها متمركز است

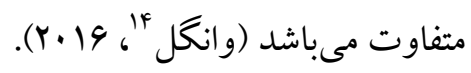

در مطالعه حاضر ارتباط بين نشخوار فكرى و كيفيت خواب بيماران افسرده اساسى يافت شد، به طورى كه افراد با نشخوار فكرى بالا، كيفيت خواب بايينترى

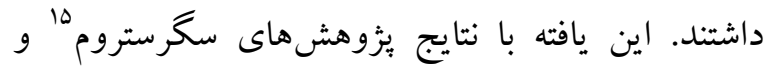

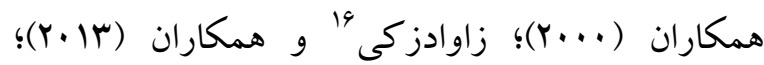

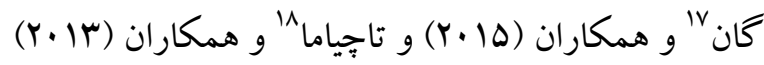
همخوانى دارد. مطالعه توماسن و همكاران نشان داد كه هوران نشخوار ذهنى به طور مستقل با عصبانى بودن و خلق

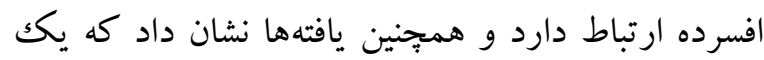
همبستگى معنادار بين نشخوار ذهنى و كيفيت خواب

11_ Van Mill

12 - Ağargün, Kara \& Solmaz

13 - Patten

14- Vengel

15 - Segerstrom

16. Zawadzki

17- Gan

18 - Tsuchiyama
بيمار بهصورت همزمان مىشود (واتكيزنز ' و همكاران، 11) بيماران افسرده اعتقاد مثبت و منفى در مورد نشخوار دارند كه باورهاى منفى به موضوعات مربوط به عدم تسليم شدن و آسيب رساندن و ييامدهاى بين فردى و اجتماعى

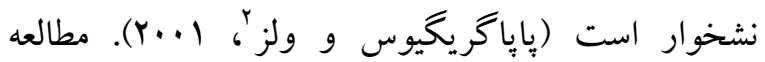
دونالدسون و همكاران نشان داد كه افسردگى با نشخوار فكرى ارتباط دارد (دونالدسون و همكاران، V ...... مطالعه ويتمر و همكاران نشان داد كه اشكال مختلف نشخوار با مكانيزم هاى مختلف شناختى همراه است و هر دو نقص ممكن است به تداوم گرايشهاى منفى مرتبط

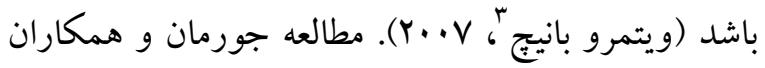

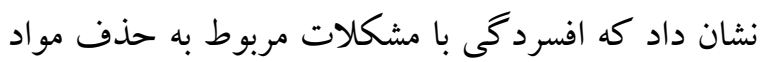
منفى نامناسب از حافظه كارى همراه است؛ و همجنين تداخل افزايشيافته از مواد منفى نامطلوب همراه با

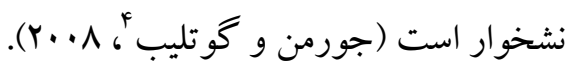

يافتهاى مطالعه حاضر نشان داد كيفيت خواب درصد از بيماران افسرده اساسى در سطح نامطلوب است. اين يافته با نتايج ويزوهشهاى يرليسه هو همكاران

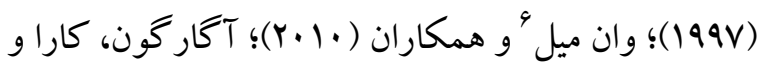

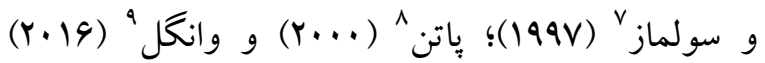
همخوانى دارد. يرليس و همكاران نشان داد كه بيماران مبتلا به افسردگى سطوح بيشتر اختلالات خواب را نشان مىدهند و شكايتهاى خواب ممكن است به دنبال

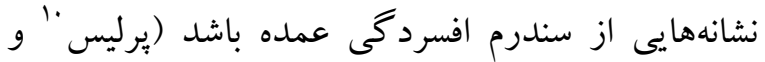

\footnotetext{
1. Watkins

2.- Papageorgiou \& Wells

3 - Whitmer \& Banich

4- Joormann \& Gotlib

5 - Perlis

6- Van Mill

7. Ağargün, Kara \& Solmaz

8 - Patten

9 - Vengel

${ }^{10}$ - Perlis
} 
نشخوار فكرى مرتبط با مرور احساسات ناشى از مسشل،

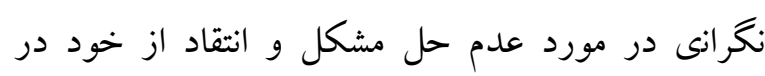
بيماران افسرده و وسواس - جبرى بيش از افر اد عادى بود.

\section{نتيجه كيرى}

يزوهش حاضر نشان داد كه بين نشخوار فكرى و كيفيت خواب در بيماران افسرده اساسى رابطه معنادار وجود دارد؛ بنابراين نشخوار فكرى منجر مىتواند با كاهش

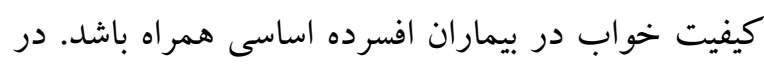
بيماران افسرده كيفيت خواب از اهميت بيشترى برخوردار است و لازم است با راهكارهاى ازجمله درمان نشخوار فكرى سلامتى آنها را ارتقاء داد؛ زيرا طبيعى است كه نشخوار ذهنى افكار منفى را به ذهن مى آورد و اين امر مىتواند در كيفيت زندگى ازجمله خواب تأثير داشته

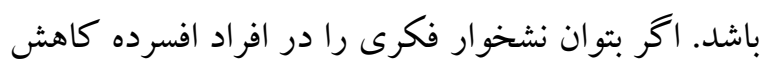
داد مىتوان كيفيت خواب را از سوى ديخر افزايش داد؛ زيرا طبق آنجه بيان شد هر جهه افراد بنا به دلايل مختلف

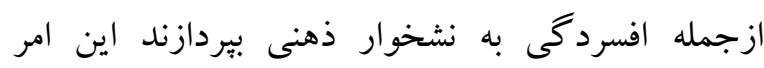
مىتواند خواب آنها را تحت تأثير قرار دهد و كيفيت

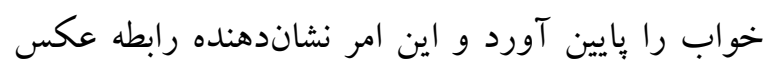
بين نشخوار ذهنى و كيفيت خواب در افراد افسرده اساسى استبنابراين كيفيت خواب كه از عناصر مهم جرخه شبانهروزى است و با تجديد قواى فيزيكى و روانى همراه است، تحت تأثير عوامل مختلفى قرار دارد و ازاينبين نشخوار فكرى به دليل تأثير گسترده بر عملكردهاى روزانه فرد مىتواند كيفيت خواب بيماران افسرده را بيشتر تحت تأثير قرار دهد. نشخوار ذهنى يكى از انواع افكار

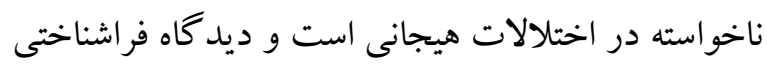
اختلالات هيجانى، نشخوار فكرى را يكى از مؤلفههاى
عينى يس از تطبيق دادن براى خلق منفى بيدا شد. تاجيياما و همكاران نشان دادند ارتباط قوى بين خواب بى كيفيت و خصومت داراى اهميت درمانى است كه براى جلو گيرى مشكلات سلامتى مىتواند در افراد استفاده

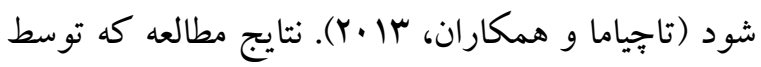
سكرستروم' و همكاران انجام شد نشان داد كه نشخوار فكرى باعث خلق منفى كه شامل نخرانى و افسردگى

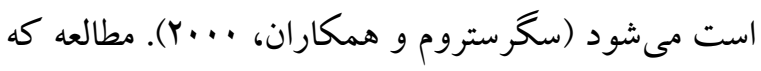
توسط زوادزك و همكاران نشخوار فكرى و نكرانى با تنهايى و افسردگى و كيفيت خواب بايين ارتباط دارد

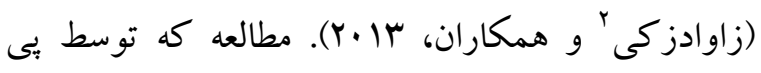
كان و همكاران انجام شد نتايج نشان داد كه تنهايى و عدم احساس آرامش كذشته بيشبينى كننده نشانهاى افسردگى در ميان سالمندان جينى در خانههاى برستارى

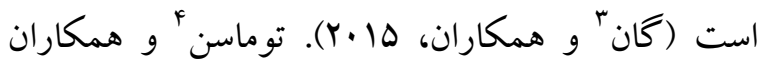
نشان دادند كه يكك ارتباط معنادار بين نشخوار ذهنى و خلق منفى و كيفيت خواب وجود دارد (تامسن و و

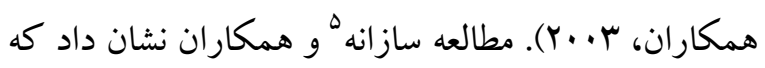
كه نشخوار فكرى باعث خلق منفى كه شامل نكرانى و افسردگى است مىشود. مطالعه زاوادزكى و همكاران نشان داد كه نشخوار فكرى و نگرانى با تنهايى و

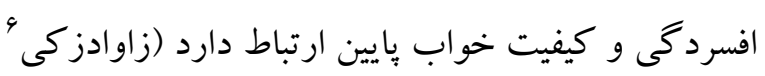

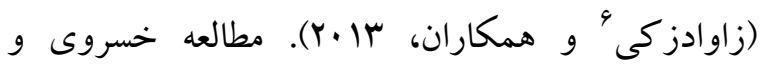
همكاران نشان مىدهد كه نشخوار فكرى در حيطههاى كرايش به تبيين گرى و مرتبط با انزوا در بيماران افسرده بهطور معنادارى بيش از افراد عادى است. همجنين، ميزان

\footnotetext{
1- Segerstrom

2- Zawadzki

3- Gan

4. Thomsen

5 - Suzanne

6- Zawadzki
} 


\section{References}

Ağargün M, Kara H, Somas M. (1997). Subjective sleep quality and suicidality in patients with major depression. Joumal of Psychiatric Research, 31(3), 377-381.

Donaldson C, Lam D, Mathews A. (2007). Rumination and attention in major depression. Behaviour research and therapy, 45(11), 2664-2678.

Gan P, Xie Y, Duan W, Deng Q, Yu X. (2015). Rumination and loneliness independently predict six-month later depression symptoms among Chinese elderly in nursing homes. PLOS One, 10(9).

Hyde JS, Mezulis AH, Abramson LY. (2008). The $\mathrm{ABCs}$ of depression: integrating affective, biological, and cognitive models to explain the emergence of the gender difference in depression. Psychological review, 115(2), 291-313.

Joormann J, Gotlib IH. (2008). Updating the contents of working memory in depression: interference from irrelevant negative material. Joumal of abnormal psychology, 117(1), 182.

Joormann J. (2006). Differential effects of rumination and dysphoria on the inhibition of imelevant emotional material: Evidence from a negative priming task. Cognitive therapy and research, 30(2), 149-160.

Lewis B. (2009). Obsession: A History, and: The Loss of Sadness: How Psychiatry Transformed Normal Sorrow into Depressive Disorder, and: Shyness: How Normal Behavior Became a Sickness, and: Bipolar Expeditions: Mania and Depression in American Culture. Literature and Medicine, 28(1), 152-171.

Lo CS, Ho SM, Hollon SD. (2008). The effects of rumination and negative cognitive styles on depression: A mediation analysis. Behaviour research and therapy, 46(4), 487-495.

Nolen-Hoeksema S. (1991). Responses to depression and their effects on the duration of depressive episodes. Joumal of abnormal psychology, 100(4), 569-582.

Papageorgiou C, Wells A. (2001). Metacognitive beliefs about rumination in recurrent major
اصلى در شروع و تداوم افسردگى مىداند كه نياز به توجه جدى دارد. در مدل شناختى بىخوابى هاروى، نكرانى و نشخوار گرى افراطى در زمينه عى ميزان خواب، سبب بروز برانخيختخى و آشفتخىهاى هيجان شده، سو گيرى توجه و ادراك نادرست در زمينهى عملكرد خواب و مدتزمان آن را به دنبال داشته و موجب شكل گيرى و تداوم آشفتخى هاى خواب مىشود. درنتيجه در اولين اقدام مىتوان با درمان نشخوار ذهنى كيفيت خواب را در افراد بالا برد و اين امر مىتواند بهجاى درمان خواب افراد به تمركز در نشخوار ذهنى يرداخت؛ بهعبارتديخر اخر نشخوار ذهنى درمان شود كيفيت خواب بهتبع آن بالا مىرود. درنهايت مىتوان با بـ تمركز بر درمان نشخوار ذهنى از بروز بسيارى از مشكلات روحى و روانى جلو گيرى كرد؛ زيرا نشخوار ذهنى مى تواند منجر به كاهش كيفيت خواب شود و اين كاهش كيفيت خواب مىتواند بر روى كل كيفيت زندگى اثر گذار باشد و كار، تحصيل هر فرد را تحت تأثير قرار دهد و حتى آرامش زندگى را از بين ببرد.

\section{سياسگز ارى}

اين مطالعه با حمايت مالى دانشگاه علوم بزشكى همدان

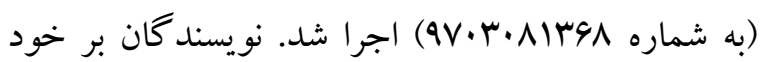
لازم مى داند از معاونت تحقيقات و فناورى دانشگاه علوم بزشكى همدان، كار كنان محترم بخشهاى روانيز بيمارستان فرشجيان سينا و بيماران بسترى اين مركز تشكر نمايند. اين مطالعه در كميته اخلاق دانشگاه علوم يزشكى ينى همدان با كد اخلاق به تصويب رسيده است. 
depression. Cognitive and Behavioral Practice, $8(2), 160-164$

Patten CA, Choi WS, Gillin JC, Pierce JP. (2000). Depressive symptoms and cigarette smoking predict development and persistence of sleep problems in US adolescents. Pediatrics, 106(2), 23-23.

Perlis ML, Giles DE, Buysse DJ, Tu X, Kupfer DJ. (1997). Self-reported sleep disturbance as a prodromal symptom in recurrent depression. Journal of affective disorders.

Rahimi-Movaghar A, Amin-Esmaeili M, Sharifi V, Hajebi A, Radgoodarzi R, Hefazi M, Motevalian A. (2014). Iranian mental health survey: design and field proced. Iranian joumal of psychiatry, 9(2), 96-109.

Roelofs J, Huibers M, Peeters F, Arntz A. (2008). Effects of neuroticism on depression and anxiety: Rumination as a possible mediator. Personality and Individual differences, 44(3), 576-586.

Rood L, Roelofs J, Bögels SM, Nolen-Hoeksema S, Schouten E. (2009). The influence of emotionfocused rumination and distraction on depressive symptoms in non-clinical youth: A meta-analytic review. Clinical psychology review, 29(7), 607-616.

Sadeghirad B, Haghdoost AA, Amin-Esmaeili M, Shahsavand Ananloo E, Ghaeli P, RahimiMovaghar A, Talebian E, Pourkhandani A, Noorbala AA, Barooti E. (2010) Epidemiology of Major Depressive Disorder in Iran: A Systematic Review and MetaAnalysis. Int J Prev Me, 1(2), 81-9.

Sarokhani D, Parvareh M, Dehkordi AH, Sayehmiri K, Moghimbeigi A. (2018). Prevalence of depression among iranian elderly: systematic review and meta-analysis. Iranian joumal of psychiatry, 13(1), 55-64.

Segerstrom SC, Tsao JC, Alden LE, Craske MG. (2000). Worry and rumination: Repetitive thought as a concomitant and predictor of negative mood. Cognitive therapy and Research, 24(6), 671-688.

Szabo YZ, Wamecke AJ, Newton TL, Valentine JC. (2017). Rumination and posttraumatic stress symptoms in trauma-exposed adults: a systematic review and meta-analysis. Anxiety, Stress, \& Coping, 30(4), 396-414.

Thomsen DK, Mehlsen MY, Christensen S, Zachariae R. (2003). Rumination relationship with negative mood and sleep quality. Personality and Individual Differences, 34(7), 1293-1301.

Tsuchiyama K, Terao T, Wang Y, Hoaki N, Goto S. (2013). Relationship between hostility and subjective sleep quality. Psychiatry research, 209(3), 545-548.

Van Mill JG, Hoogendijk WJ, Vogelzangs N, van Dyck R, Penninx BW. (2010). Insomnia and sleep duration in a large cohort of patients with major depressive disorder and anxiety disorders. Joumal of Clinical Psychiatry, 71(3), 239.

Vengel D. (2016). The relationships among mindfulness, rumination, and stress-related sleep disturbance (Doctoral dissertation, Alliant Intemational University).

Watkins ER, Mullan E, Wingrove J, Rimes K, Steiner H, Bathurst N, Eastman R, Scott J. (2011). Rumination-focused cognitive-behavioural therapy for residual depression: Phase II randomised controlled trial. The British Journal of Psychiatry, 199(4), 317-322.

Whitmer AJ, Banich MT. (2007). Inhibition versus switching deficits in different forms of rumination. Psychological science, 18(6), 546553.

Zawadzki MJ, Graham JE, Gerin W. (2013). Rumination and anxiety mediate the effect of loneliness on depressed mood and sleep quality in college students. Health Psychology, 32(2), 212-222. 